\title{
Biofilm-producing ability and efficiency of sanitizing agents against Prototheca zopfii isolates from bovine subclinical mastitis
}

\author{
Juliano Leonel Gonçalves, ${ }^{*}$ Sarah Hwa In Lee, $†$ Eurico de Paula Arruda,ł Débora Pedroso Galles, $†$ \\ Vinícius Camargo Caetano, $\ddagger$ Carlos Augusto Fernandes de Oliveira, † Andrezza Maria Fernandes, $\ddagger$ \\ and Marcos Veiga dos Santos*1 \\ *Department of Animal Sciences, School of Veterinary Medicine and Animal Sciences, \\ †Department of Food Engineering, School of Animal Sciences and Food Engineering, and \\ †Department of Veterinary Medicine, School of Animal Sciences and Food Engineering, University of São Paulo (USP), Pirassununga, \\ SP, Brazil 13635-900
}

\begin{abstract}
The objectives of the present study were to evaluate (1) the capacity of the microalga Prototheca zopfii isolated from subclinical bovine mastitis cases to form biofilms; and (2) the resistance of these isolates to sanitizing agents. Ten isolates of $P$. zopfii from cows with subclinical mastitis (somatic cell count $>200 \times$ $10^{3}$ cells $/ \mathrm{mL}$ ), distributed in 5 dairy farms, were evaluated for their capacity to form biofilms in polystyrene microplate assays and stainless steel coupons, at $25^{\circ} \mathrm{C}$ and $37^{\circ} \mathrm{C} \pm 1{ }^{\circ} \mathrm{C}$. Prototheca zopfii were isolated from milk samples via microbiological culture and analyzed by $18 \mathrm{~S}$ rRNA gene sequencing. Biofilm formation on the coupons was observed by scanning electron microscopy. The resistance to sanitizing agents was assessed using the biofilm-forming P. zopfii isolates in stainless steel coupon assays, which were subjected to 3 sanitizers: peracetic acid, sodium hypochlorite, and iodine solution. To evaluate resistance to the sanitizers, the minimum inhibitory concentration (MIC) technique was performed using decreasing concentrations of the sanitizing agents $(20,10,5,2.5,1.25,0.625,0.312$, $0.156,0.078,0.039$, and $0.019 \mathrm{~g} / \mathrm{L})$. After inoculating the isolates, all concentrations were evaluated at 3 distinct incubation periods $(24,48$, and $72 \mathrm{~h}$ ) to assess the effect of incubation time on the MIC. Using the polystyrene microplate assays, 1 isolate showed weak biofilm production, 5 moderate, and 4 strong, when incubated at $25^{\circ} \mathrm{C} \pm 1$. For isolates incubated at $37^{\circ} \mathrm{C}$ $\pm 1,6$ showed weak biofilm production and 4 moderate. All $P$. zopfii isolates $(\mathrm{n}=10)$ had the capacity to form biofilms on stainless steel coupons. The longer the incubation period of the $P$. zopfii isolates at different dilutions, the greater the concentrations of sanitizer needed to prevent growth of the microalgae under the
\end{abstract}

Received December 16, 2014.

Accepted February 20, 2015.

${ }^{1}$ Corresponding author: mveiga@usp.br tested conditions. We detected a significant effect of sanitizer and time of incubation $(24,48$, and $72 \mathrm{~h})$ on MIC values against $P$. zopfii isolates. The isolates were sensitive in vitro to peracetic acid $\left(\mathrm{MIC}_{90} \geq 0.019 \mathrm{~g} / \mathrm{L}\right)$, sodium hypochlorite $\left(\mathrm{MIC}_{90} \geq 0.312 \mathrm{~g} / \mathrm{L}\right)$, and iodine solution $\left(\mathrm{MIC}_{90} \geq 0.625 \mathrm{~g} / \mathrm{L}\right)$, after $24 \mathrm{~h}$ of incubation (where $\mathrm{MIC}_{90}=$ concentration needed to inhibit $90 \%$ of isolates). Of the tested sanitizers, peracetic acid had the greatest efficiency against $P$. zopfii. We conclude that P. zopfii isolates are capable of biofilm production, which may contribute to their persistence in a milking and dairy environment.

Key words: subclinical mastitis, biofilm-producing isolate, sanitizer, Prototheca zopfii

\section{INTRODUCTION}

The occurrence of mastitis caused by the microalga Prototheca zopfii has been described in several countries (Corbellini et al., 2001; Möller et al., 2007; Osumi et al., 2008; Marques et al., 2010b; Ricchi et al., 2010; Pieper et al., 2012). The frequency of bovine protothecal mastitis caused by $P$. zopfii has been increasing worldwide, which may represent a serious problem due to the inherent resistance to routine therapy of these microalgae (Cunha et al., 2010; Pieper et al., 2012; Ricchi et al., 2010). This resistance is associated with the capacity of the microalgae to infect and survive in macrophages and to invade mammary tissue, making them responsible for a persistent infection with intermittent shedding of $P$. zopfii in milk (Marques et al., 2006).

The treatment of mastitis caused by Prototheca spp. with antimicrobials produces only temporary improvement of clinical signs due to the low rate of cure in vivo, and because of this, the causative agent is not eliminated (Costa et al., 1996). Therefore, culling cows infected with $P$. zopfii is one of the recommended control measures to reduce the disease (Jánosi et al., 2001).

The main risk factors associated with mastitis caused by $P$. zopfii in dairy herds are transmission between 
infected and healthy cows during milking (Jánosi et al., 2001), the use of previous or intensive treatment with antibiotics (Corbellini et al., 2001; Pieper et al., 2012), and deficiencies in hygiene during premilking preparation of dairy cows. Furthermore, P. zopfii survive in feces and are able to contaminate practically every environment that comes in contact with bovine feces. In the same manner, feces of calves fed milk contaminated with P. zopfii may be an important source of environmental contamination (Jánosi et al., 2001).

Prototheca zopfii shows high resistance to heat treatment (Melville et al., 1999; Lassa et al., 2011). Such resistance represents a risk to the consumption of milk and dairy products, because heat treatment is used to eliminate many pathogenic agents (Melville et al., 1999). Additionally, cases of human protothecosis caused by P. zopfii, Prototheca blaschkeae, and Prototheca wickerhamii isolated from cows with subclinical mastitis have been reported (Melville et al., 1999; Marques et al., 2006; Lass-Flörl and Mayr, 2007).

In the milking and dairy environments, surfaces such as stainless steel, glass, rubber, and polypropylene can be contaminated by microorganisms. Subsequently, the microorganisms may multiply and produce biofilms (Pompermayer and Gaylarde, 2000; Davies, 2003). The time required for multiplication is an important factor in biofilm production and is associated with the frequency of equipment cleaning (Gibson et al., 1999). Marques et al. (2010b) suggested that microalgae form cellular clusters and, in this manner, have resistance to heat treatment. Davies (2003) reported that cases of chronic infection are generally due to resistance of biofilm-producing bacteria to conventional antimicrobial treatments.

Considering the difficulty of treating mastitis caused by Prototheca spp., the hypothesis of the present study is that the $P$. zopfii isolates, with biofilm production capacity, are more resistant to sanitizers such as peracetic acid, sodium hypochlorite, and iodine solution commonly used in predipping. To our knowledge, no previous studies have evaluated the ability of $P$. zopfii isolated from bovine mastitis to produce biofilms. The objectives of the present study were to evaluate (1) the capacity of $P$. zopfii isolates from subclinical mastitis cases to produce biofilm; and (2) the resistance of $P$. zopfii isolates to sanitizing agents.

\section{MATERIALS AND METHODS}

\section{Sampling and Isolation of Prototheca}

A total of 285 dairy cows, distributed in 21 dairy farms from Pirassununga (São Paulo State, Brazil) were enrolled in this study. Mammary quarter milk samples ( $\mathrm{n}=1,140$ ) were subjected to screening for subclinical mastitis cases caused by Prototheca spp. Subclinical protothecal mastitis was defined as a lack of clinical signs, isolation of Prototheca spp., and SCC >200 $\times$ $10^{3}$ cells $/ \mathrm{mL}$. On the other hand, mammary quarters were considered healthy when they had no isolation of microorganisms following a 72-h incubation after milk sampling and SCC $<200 \times 10^{3}$ cells/mL (Bradley and Green, 2005). The SCC was determined by flow cytometry using a Fossomatic FC (Fossomatic FC, Rellingen, Germany).

Prototheca spp. isolates were identified according to Oliver et al. (2004). Briefly, $0.01 \mathrm{~mL}$ of milk was spread onto a quadrant of a blood agar plate (Becton, Dickinson and Co., Sparks, MD) and incubated aerobically at $37^{\circ} \mathrm{C} \pm 1^{\circ} \mathrm{C}$ for up to $48 \mathrm{~h}$. After growth on blood agar, the isolates were streaked on a plate of Sabouraud dextrose agar (Oxoid Ltd., Basingstoke, UK) and incubated at $37^{\circ} \mathrm{C} \pm 1^{\circ} \mathrm{C}$ for up to $72 \mathrm{~h}$. After the incubation period, bacterial colonies were classified according to their morphological features (color, appearance, size, and presence of hemolysis), and counts (cfu/mL) of Prototheca spp. were determined. Colonies grown in blood agar and Sabouraud dextrose that had creamy and white or greyish-white characteristics were identified as Prototheca spp. by light microscopy. Prototheca spp. identification was based on colony morphology and on smears by Gram staining and methylene blue technique (Oliver et al., 2004). The isolates of Prototheca spp. were cryopreserved in triplicate at $-20^{\circ} \mathrm{C}$ in tryptone soy broth (TSB; Oxoid Ltd.) supplemented with $0.6 \%$ yeast extract (HiMedia Laboratories, Mumbai, India) and 20\% sterile glycerol (Sigma Aldrich, St. Louis, MO), for further analysis.

\section{DNA Extraction and PCR}

Before DNA extraction, all Prototheca spp. isolates were cultured overnight on TSB supplemented with $0.6 \%$ yeast extract (HiMedia Laboratories) at $37^{\circ} \mathrm{C}$ under aerobic conditions to evaluate the purity of the colonies. Subsequently, a single Prototheca spp. colony was resuspended in $1 \mathrm{~mL}$ of autoclaved Milli-Q water (Millipore Corp., Bedford, MA); a 0.5-mL aliquot from the autoclaved water volume was further used during the extraction process. The aliquot was heat shocked twice $\left(99^{\circ} \mathrm{C} \times 10 \mathrm{~min}\right)$ and then rapidly frozen. The microbial DNA was extracted by using the phenolchloroform method (Sambrook et al., 1989). Briefly, $500 \mu \mathrm{L}$ of the aliquot was mixed with an equal amount of phenol-chloroform (Sigma Aldrich, São Paulo, Brazil) and then centrifuged at $14,000 \times g$ for $10 \mathrm{~min}$ at 
$4^{\circ} \mathrm{C}$. After centrifugation, the supernatant was removed and the pellet was again mixed with an equal volume of chloroform. The aliquot was re-centrifuged under the same conditions. Sodium acetate at $1 M(1 / 10$ of the collected volume) was added to a new sterile tube with supernatant and cold isopropanol (equal volumes; Merck, Sharp \& Dohme, São Paulo, SP, Brazil) in order, and centrifuged at $14,000 \times g$ for $10 \mathrm{~min}$ at $4^{\circ} \mathrm{C}$. All of the supernatant was carefully discarded so as to not disrupt the pellet, and the tube was left to dry on clean paper for $5 \mathrm{~min}$. The pellet was then washed with $70 \%$ ethanol (Merck, Sharp \& Dohme, São Paulo, SP, Brazil) and centrifuged at $14,000 \times g$ for $10 \mathrm{~min}$ at $4^{\circ} \mathrm{C}$. The supernatant was discarded and the tube left to dry on paper. Finally, the extracted DNA was hydrated in $50 \mu \mathrm{L}$ of DNase-free water and incubated at $65^{\circ} \mathrm{C}$ for $1 \mathrm{~h}$, and stored at $-20^{\circ} \mathrm{C}$ until further use. The DNA was quantified using a spectrophotometer (NanoDrop 2000, Thermo Scientific, Toronto, ON, Canada) and its integrity observed [in the $0.6 \%$ agarose gel (Trisacetate-EDTA $1 \times$ ) for the presence of a single band of DNA; up to $5 \mu \mathrm{L}$ of genomic DNA was applied in each well and ran at $120 \mathrm{~V}$ for $30 \mathrm{~min}$; Promega, Madison, $\mathrm{WI}]$.

The amplification reactions of DNA were done with final volumes of $25 \mu \mathrm{L}$ containing $12.5 \mu \mathrm{L}$ of $2 \times$ Master Mix (Promega), $1 \mu \mathrm{L}$ of each primer $(10 \mu M), 0.5 \mu \mathrm{L}$ of $\mathrm{MgCl}_{2}(1.5 \mathrm{mM}), 1 \mu \mathrm{L}$ of deoxynucleotide triphosphates (dNTP, $0.2 \mathrm{mM}$; Invitrogen, São Paulo, SP, Brazil), $0.2 \mu \mathrm{L}$ of GoTaq (Invitrogen), $50 \mathrm{ng}$ of DNA, and a final volume of Ultrapure water (Sigma-Aldrich, São Paulo, Brazil). The primers were the same as those designed by Huss et al. (1999) for the 18S rDNA gene (forward: 5'-WACCTGGTTGATCCTGCCAGT-3'; reverse: 5'-GATCCTTCYGCAGGTTCACCTAC-3'; $\mathrm{W}$ and $\mathrm{Y}$ represent possible bases $\mathrm{A}$ or $\mathrm{T}$ and $\mathrm{C}$ or $\mathrm{T}$ in the sequencing of Prototheca spp., respectively). The amplification reaction was performed in a thermal cycler (Master Cycler, Eppendorf, Hamburg, Germany), programmed for 1 cycle at $95^{\circ} \mathrm{C}(4 \mathrm{~min})$, followed by 35 cycles at $95^{\circ} \mathrm{C}(1 \mathrm{~min}), 54^{\circ} \mathrm{C}(1 \mathrm{~min})$, and $72^{\circ} \mathrm{C}$ $(2.5 \mathrm{~min})$, and 1 final cycle at $72^{\circ} \mathrm{C}(5 \mathrm{~min})$, according to the standardized protocol in Marques et al. (2008).

Prothoteca zopfii ATCC 16533 was used as a positive control and Ultrapure water as a negative control. The PCR product underwent electrophoresis at $110 \mathrm{~V}$ for 30 min on a PowerPac Basic (BioRad, Hercules, CA), using 1\% agarose gel (Promega) prepared using Trisacetate-EDTA buffer, and stained with SYBR Safe DNA gel stain (Invitrogen). The 100-bp DNA Ladder (Life Technologies, Gaithersburg, MD) marker was used as a molecular weight indicator. Gels were photo- graphed with the Gel Documentation System BioSens SC750 (Bio-Tech Co. Ltd., Shanghai, China) using the GeneScope V1.73 program.

\section{Sequencing Reactions and Precipitation Protocols}

Specific amplification bands (about 1,800 bp) were cut from the gel and purified using the GFX TM PCR DNA and Gel Band Purification kit (GE Healthcare, Munich, Germany), according to the manufacturer's specifications. The sequencing reactions were performed on a Veriti thermal cycler (Applied Biosystems, Paisley, UK), using the following cycle conditions: $95^{\circ} \mathrm{C}$ for $4 \mathrm{~min}$, and 25 cycles at $95^{\circ} \mathrm{C}$ for $20 \mathrm{~s}, 50^{\circ} \mathrm{C}$ for 15 $\mathrm{s}$, and $60^{\circ} \mathrm{C}$ for $4 \mathrm{~min}$. The PCR products were precipitated using absolute ethanol, EDTA, and sodium acetate. Formamide was added to separate the double helix before sequencing. The sequencing reaction was obtained using the Big-Dye Terminator v3.1 Cycle Sequencing kit on the ABI3500 Genetic Analyzer (Applied Biosystems, Foster City, CA), according to the manufacturer's specifications.

The electrospherograms obtained from the sequencing reaction on the ABI3500 platform were edited using the Genious R6 software (Biomatters Ltd., Auckland, New Zealand), manually removing the low quality initial and final bases [high-quality $(\mathrm{HQ})$ reads $<30$ ], as well as the undefined bases due to background throughout the sequence. The edited sequences were then aligned, when possible, using the identity criteria. The final consensus sequences generated by this process were compared against the National Center for Biotechnology Information nucleotide database, using the BLAST tool and the Megablast algorithm, for species identification (http://blast.ncbi.nlm.nih.gov/blast/ Blast.cgi).

\section{Prototheca spp. Biofilm Production Assays}

Polystyrene Microplates. The capacity of the Prototheca spp. isolates $(\mathrm{n}=10)$ to produce biofilm was determined according to the procedure described by Stepanović et al. (2003). Each isolate was briefly resuspended in TSB supplemented with $0.6 \%$ yeast extract (HiMedia Laboratories), incubated at $37^{\circ} \mathrm{C} \pm$ $1^{\circ} \mathrm{C}$ for $24 \mathrm{~h}$, and diluted to $10^{8}$ cells $/ \mathrm{mL}(0.5$ on MacFarland scale).

Aliquots of $200 \mu \mathrm{L}$ of each isolate, in triplicate, were transferred to 96 -well flat-bottomed sterile polystyrene microplates and incubated simultaneously at $25^{\circ} \mathrm{C}$ and $37^{\circ} \mathrm{C} \pm 11^{\circ} \mathrm{C}$ for $24 \mathrm{~h}$. After incubation, the microplates were agitated, fixed, stained with crystal violet for 5 
min, dried, and resolubilized with $33 \%$ (vol/vol) glacial acetic acid. The biofilm production on the microplates was measured using an ELISA reader (Labsystems Inc., Helsinki, Finland) fixed at $620 \mathrm{~nm}$, and the results were expressed as optical density (OD) values. The negative control triplicates contained only sterile TSB, were prepared as described by Stepanović et al. (2003), and were used as reference to determine the capacity of the Prototheca spp. isolates to produce biofilm. The mean values of the negative controls $\left(\mathbf{O D}_{\mathrm{NC}}\right.$; Staphylococcus epidermidis ATCC 12228) were $0.1246 \pm 0.0063$ and $0.1754 \pm 0.0061$ for samples incubated at $25^{\circ} \mathrm{C}$ and $37^{\circ} \mathrm{C} \pm 1^{\circ} \mathrm{C}$, respectively. Isolates of Prototheca spp. were considered biofilm producers when the OD values were 3 times greater than the standard deviation (SD) of the $\mathrm{OD}_{\mathrm{NC}}$ mean value. A positive control was also included (Staphylococcus epidermidis ATCC 35983). The mean values of the positive controls $\left(\mathbf{O D}_{\mathbf{P C}}\right)$ were $0.3873 \pm 0.0436$ and $0.4483 \pm 0.0188$, which were incubated at $25^{\circ} \mathrm{C}$ and $37^{\circ} \mathrm{C} \pm 1$, respectively. Briefly, the cutoff OD was defined as $3 \mathrm{SD}$ above the mean OD of the negative control. In addition, the capacity of the isolates to produce biofilm was classified as weak $\left(\mathrm{OD}_{\mathrm{NC}}<\mathrm{OD} \leq 2 \times \mathrm{OD}_{\mathrm{NC}}\right)$, moderate $\left(2 \times \mathrm{OD}_{\mathrm{NC}}<\mathrm{OD}\right.$ $\left.\leq 4 \times \mathrm{OD}_{\mathrm{NC}}\right)$, or strong $\left(\mathrm{OD}>4 \times \mathrm{OD}_{\mathrm{NC}}\right)$. Differences in the degree of biofilm formation by the triplicates were examined using the Friedman test, followed by the Wilcoxon-signed rank test. $P$-values of 0.05 were considered significant (Stepanović et al., 2003).

Scanning Electron Microscopy. The capacity to produce biofilm on the stainles steel was evaluated by scanning electron microscopy, according to protocols described by Chandra et al. (2008) and Kadouri and O'Toole (2005). Two stainless steel coupons $(1.0 \times$ $1.0 \mathrm{~cm}$ ), one for each isolate, were introduced into the inferior portion of the wells of a flat-bottomed sterile polystyrene microplate ( 24 wells). Then, $2 \mathrm{~mL}$ of suspension of each isolate was added, in duplicate, to the wells and incubated at $25^{\circ} \mathrm{C}$ and $37^{\circ} \mathrm{C} \pm 1^{\circ} \mathrm{C}$ for $48 \mathrm{~h}$ without agitation. After incubation, the stainless steel coupons were washed with phosphate buffer to remove nonadherent cells and fixed in modified Karnovsky glutaraldehyde solution for at least $3 \mathrm{~h}$. Next, they were washed with $0.05 M$ cacodylate buffer. The coupons were subsequently washed with autoclaved distilled water and submitted to dehydration using increasing concentrations of acetone $(25,50,75$, and $100 \%)$, remaining in each concentration for $10 \mathrm{~min}$. After fixation and dehydration, the acetone evaporated and the coupons were refrigerated $\left(4^{\circ} \mathrm{C} \pm 1\right)$ until visualization using scanning electron microscopy (SEM-Hitachi TM300, Hitachi, São Paulo, Brazil).

\section{Profile of Resistance to Sanitizers and MIC}

The resistance profile to sanitizing agents was determined on Prototheca spp. isolates that were shown to produce biofilm in the stainless steel coupon assays $(\mathrm{n}=10)$. Three sanitizers were evaluated: peracetic acid solution (77240, Sigma-Aldrich Co., Steinheim, Germany), iodine solution (38060, Sigma-Aldrich Co.), and sodium hypochlorite (425044, Sigma-Aldrich Co., St. Louis, MO).

The MIC technique was used to determine the resistance profile of Prototheca spp. isolates to the sanitizers. This technique quantitatively measures the in vitro activity of an antimicrobial agent against a certain microorganism (NCCLS, 2000). To perform the test, 12 tubes were prepared with culture medium (TSB supplemented with yeast extract at $0.6 \%$ ), to which decreasing concentrations of the sanitizing agents (20, $10,5,2.5,1.25,0.625,0.312,0.156,0.078,0.039$, and $0.019 \mathrm{~g} / \mathrm{L}$ ) were added. The tubes were then inoculated with a standard suspension of $100 \mu \mathrm{L}$ of each tested isolate. After incubation at $30^{\circ} \mathrm{C} \pm 1^{\circ} \mathrm{C}, 3$ readings (at 24,48 , and $72 \mathrm{~h}$ ) were taken by visual comparison of the tubes. All isolates were evaluated, in duplicate, to determine in vitro resistance to sanitizers, totalling 720 assays. Furthermore, for each tested isolate, 1 negative control (culture medium and sanitizing agent) and 1 positive control (strain ATCC 16533 of Prothoteca pzofii and TSB) were included. The MIC was determined as the lowest concentration of a sanitizing agent that prevented visible growth (without turbidity) of the microalgae (NCCLS, 2000). To confirm the dilutions that prevented growth of Prototheca spp., $100 \mu \mathrm{L}$ of each dilution was inoculated in Sabouraud dextrose agar according to Marques et al. (2006). Dilutions that did not show turbidity (no growth) in vitro were considered inhibitors (Marques et al., 2010a).

Results for peracetic acid, sodium hypochlorite, and iodine solutions were summarized by calculating the $\mathrm{MIC}_{50}$ and $\mathrm{MIC}_{90}$ as described by Cortinhas et al. (2013), where $\mathrm{MIC}_{50}$ and $\mathrm{MIC}_{90}$ indicate $\mathrm{MIC}$ required to inhibit growth of $50 \%$ and $90 \%$ of the isolates, respectively. Survival analysis was used to determine whether the sanitizers had different MIC. The range of sanitizer concentrations tested was used as the time variable in the survival analysis. Inhibition of Prototheca spp. growth was used as the event, and isolates that had growth at the highest concentration tested were defined as not inhibited. Kaplan-Meier survival curves were based on 3 different incubation times (24, 48 and $72 \mathrm{~h}$ ) of peracetic acid, sodium hypochlorite, and iodine solution concentrations, and the null hypothesis 
Table 1. Biofilm production of Prototheca zopfii isolated from bovine subclinical mastitis ${ }^{1}$

\begin{tabular}{|c|c|c|c|c|c|c|c|c|}
\hline $\begin{array}{l}\text { Temperature and } \\
\text { incubation time }\end{array}$ & \multicolumn{2}{|r|}{ Weak } & \multicolumn{2}{|r|}{ Moderate } & \multicolumn{2}{|r|}{ Strong } & \multicolumn{2}{|r|}{ Total } \\
\hline $37^{\circ} \mathrm{C}, 48 \mathrm{~h}$ & $6(60)$ & $0.2964 \pm 0.0526$ & $4(40)$ & $0.6405 \pm 0.2689$ & - & - & $10(100)$ & $0.4341 \pm 0.1391$ \\
\hline
\end{tabular}

${ }^{1}$ Capacity of the isolates to produce biofilms was classified according to Stepanović et al. (2003). The average optical density (OD) values of the negative controls $\left(\mathrm{OD}_{\mathrm{NC}}\right.$ ) were $0.1246 \pm 0.0063$ (mean $\pm \mathrm{SD}$ ) and $0.1754 \pm 0.0061$, for incubations at $25^{\circ} \mathrm{C}$ and $37^{\circ} \mathrm{C} \pm 1^{\circ} \mathrm{C}$, respectively. The average values of the positive controls $\left(\mathrm{OD}_{\mathrm{PC}}\right)$ were $0.3873 \pm 0.0436$ and $0.4483 \pm 0.0188$, for incubations at $25^{\circ} \mathrm{C}$ and $37^{\circ} \mathrm{C} \pm 11^{\circ} \mathrm{C}$, respectively. The isolates were classified as weak $\left(\mathrm{OD}_{\mathrm{NC}}<\mathrm{OD} \leq 2 \times \mathrm{OD}_{\mathrm{NC}}\right)$, moderate $\left(2 \times \mathrm{OD}_{\mathrm{NC}}<\mathrm{OD} \leq 4 \times \mathrm{OD}_{\mathrm{NC}}\right)$, or strong $\left(\mathrm{OD}>4 \times \mathrm{OD}_{\mathrm{NC}}\right)$.

of no difference in the survival strata (concentration at inhibition) was tested via log-rank and Wilcoxon tests.

\section{RESULTS AND DISCUSSION}

All Prototheca spp. isolates $(\mathrm{n}=10)$ were confirmed by $18 \mathrm{~S}$ rRNA gene sequencing to be $P$. zopfii. Mammary quarters infected with $P$. zopfii had average $\operatorname{lnSCC}$ of $7.77 \pm 2.14 \times 10^{3}$ cells $/ \mathrm{mL}$ and $>10 \mathrm{cfu} / 0.01 \mathrm{~mL}$ of milk spread on blood agar.

In the present study, 5 of 21 dairy farms had positive diagnoses of $P$. zopfii. The number of farms on which P. zopfii was detected (23.8\%) was less than that (75\%) reported by Ricchi et al. (2010) in Italy. The frequency of subclinical mastitis caused by $P$. zopfii found in the present study at the quarter level $(0.9 \%)$ was less than that reported in Brazil (18.5\% at the quarter level) by Costa et al. (1997), probably because none of the farms enrolled in the present study had reported outbreaks caused by $P$. zopfii. Frequency of IMI caused by $P$. zopfii depends on control of risk factors, the environment, and the immune response of the animal; however, complete elimination of microalgae from the mammary gland is difficult, because P. zopfii causes chronic and persistent mastitis with intermittent elimination of this pathogen (Roesler and Hensel, 2003).

\section{Polystyrene Microplate Assay for Biofilm Production}

In the present study, all $P$. zopfii isolates $(\mathrm{n}=10)$ had the capacity to produce biofilm as assessed by the polystyrene microplate assay method. Of isolates that were incubated at $25^{\circ} \mathrm{C} \pm 1(\mathrm{n}=10), 1$ showed weak biofilm production, 5 moderate, and 4 strong $(P<$ 0.02; Table 1). Of those isolates incubated at $37^{\circ} \mathrm{C} \pm$ $1^{\circ} \mathrm{C}(\mathrm{n}=10), 6$ showed weak biofilm production and 4 moderate $(P<0.01$; Table 1$)$. Our results suggest that biofilm production capacity may vary according to incubation temperature, because at $25^{\circ} \mathrm{C}, 4$ isolates had strong biofilm production, whereas none showed strong biofilm production when incubated at $37^{\circ} \mathrm{C} \pm$ $1^{\circ} \mathrm{C}$. To our knowledge, no previous study has evaluated the relationship between biofilm production capacity of bacteria versus microalgae associated with subclinical mastitis.

The clustering behavior of microorganisms in biofilms depends on the environmental conditions and the growth-promoting genes of the microorganism. Gerstel and Romling (2001) reported that the multi-cellular expression of the agfD gene of Salmonella typhimurium leads to production of polymers, thin agglomerates of fimbria and cellulose that form the extracellular matrix. Furthermore, Knobloch et al. (2001) reported that intercellular polysaccharide adhesin, originally from the cluster gene $i c a A D B C$, is essential in biofilm production by Staphylococcus epidermidis multi-cells. Thus, different microorganisms express specific genes, which lead to the production of extracellular matrix-forming substances that are directly related to the production of biofilm.

Although $P$. zopfii is a microalga, some comparisons of the present study were made with bacterial models used for assessing biofilm production. This is because microalgae produce biofilms in a similar manner to bacteria; initially, they agglomerate and then produce the extracellular matrix. Therefore, assessment of biofilm production by algae may be similar to that used for other bacterial agents (Stepanović et al., 2003; Nagai et al., 2013; Lee et al., 2014).

The results of the present study indicate the capacity to produce biofilm by $P$. zopfii; however, further studies on gene expression are needed to identify the specific genes associated with biofilm production by $P$. zopfii.

\section{Scanning Electron Microscopy}

All P. zopfii isolates that produced biofilm on the stainless steel coupons were submitted to scanning electron microscopy. The coupons incubated in microplates at $25^{\circ} \mathrm{C} \pm 1^{\circ} \mathrm{C}(\mathrm{n}=10)$ showed greater microalgae clustering, with different sizes of endospores (Figure $1 \mathrm{~A}$ and 1B). Similarly, P. zopfii isolates were able to 
A

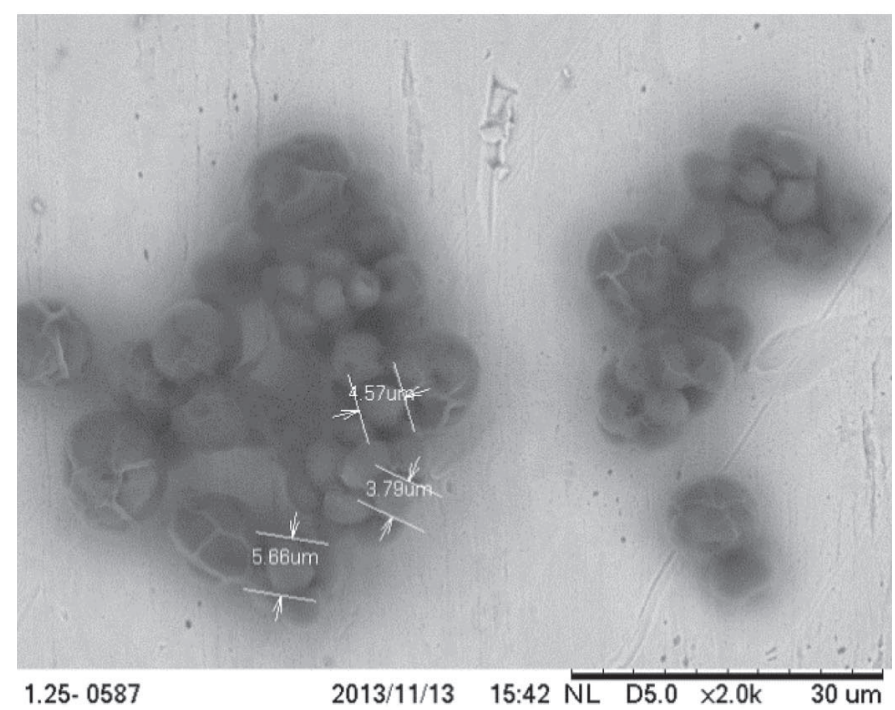

\section{B}

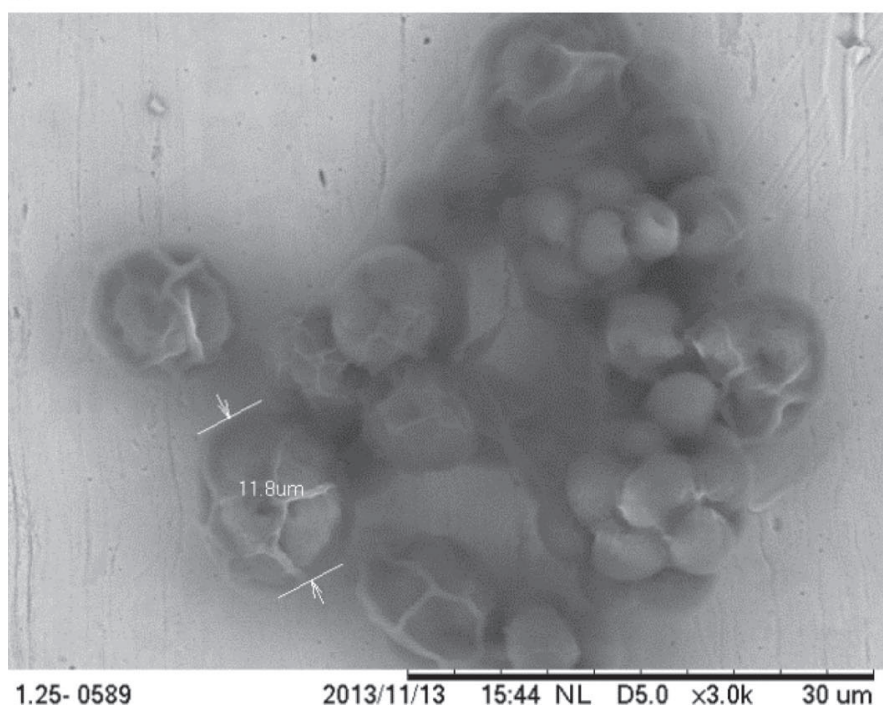

Figure 1. Biofilm production in stainless steel coupons by Prototheca zopfii (isolate 1 ) at $25^{\circ} \mathrm{C}$, showing release of endospores after rupture and endospores ranging from 3.79 to $5.66 \mu \mathrm{m}(\mathrm{A})$, and larger endospores (11.8 $\mu \mathrm{m}$; B; scanning electron microscopy).

produce biofilm at $37^{\circ} \mathrm{C} \pm 1^{\circ} \mathrm{C}(\mathrm{n}=10)$, although the microalgae cells were surrounded by a dark structure, similar to the lipidic layer of the cellular wall (Figure 2 ). This structure was similar to sporangia (enclosures in which spores form) and might have prevented greater clustering of the microalgae on the surface of the stainless steel coupons when incubated at $37^{\circ} \mathrm{C}$.

Microalgae reproduce asexually by internal septation (endosporulation). Prototheca spp. are organized in a cell of oval or spherical shape called the mother cell (sporangium), and a viable mother cell may give rise to 2 to 16 daughter cells, known as endospores (Janosi et al., 2001; Buzzini et al., 2004; Camboim et al., 2010). The endospores remain inside the sporangium, surrounded by a trilaminar capsule of sporopolenine, which, when ruptured, releases the cells and a new reproductive cycle begins. In this study, the release of the endospores was observed in isolates incubated at the lower incubation temperature $\left(25^{\circ} \mathrm{C} \pm 1^{\circ} \mathrm{C}\right.$; Figure $1)$. Once the sporangium ruptures, the endospores need to cluster to initiate a new reproductive cycle. This clustering period is the initial phase of biofilm production (Davies, 2003).

The use of stainless steel coupons was described by Lee et al. (2014) to evaluate biofilm production of Staphylococcus aureus from mastitis cases and in milking environments. Considering that stainless steel is a widely used material, it simulates the biofilm production that can occur in milking and dairy environments with deficient sanitizing equipment and utensils. Furthermore, Osumi et al. (2008) reported that an infection route of $P$. zopfii might be contamination of milking equipment. Our results on the capacity of $P$. zopfii to produce biofilm agree with the findings of Marques et al. (2010b), that P. zopfii form cellular clusters and thus have resistance to heat treatment.

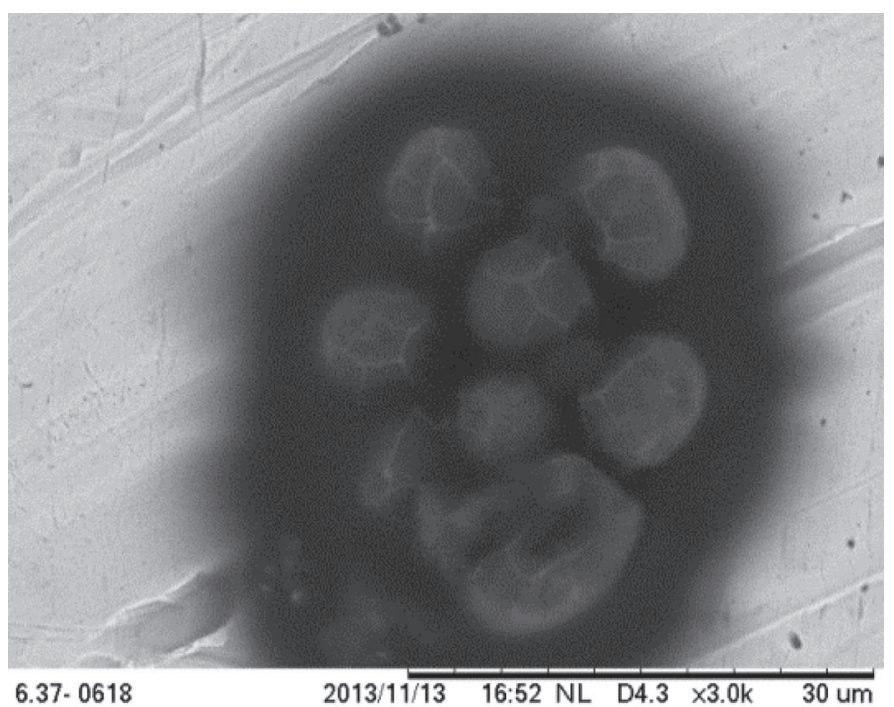

Figure 2. Biofilm production in stainless steel coupons by Prototheca zopfii at $37^{\circ} \mathrm{C}$. All Prototheca zopfii isolates were surrounded by a dark structure, similar to the lipidic layer of the cellular wall (scanning electron microscopy). 
Table 2. Number of Prototheca zopfii isolated for different MIC (NCCLS, 2000) of peracetic acid, sodium hypochlorite, and iodine solution used in vitro as sanitizers against $P$. zopfii ${ }^{1}$

\begin{tabular}{|c|c|c|c|c|c|c|c|c|c|c|c|c|c|c|}
\hline $\begin{array}{l}\text { Incubation } \\
\text { time/sanitizer }\end{array}$ & \multicolumn{11}{|c|}{$\operatorname{MIC}(\mathrm{g} / \mathrm{L})$} & $\mathrm{MIC}_{50}{ }^{2}$ & $\mathrm{MIC}_{90}{ }^{2}$ & $P$-value ${ }^{3}$ \\
\hline Peracetic acid & 10 & 0 & 0 & 0 & 0 & 0 & 0 & 0 & 0 & 0 & 0 & 0.019 & 0.019 & \multirow[t]{3}{*}{$<0.001$} \\
\hline Sodium hypochlorite & 0 & 0 & 1 & 6 & 2 & 1 & 0 & 0 & 0 & 0 & 0 & 0.156 & 0.312 & \\
\hline Iodine solution & 1 & 0 & 2 & 4 & 1 & 2 & 0 & 0 & 0 & 0 & 0 & 0.156 & 0.625 & \\
\hline \multicolumn{15}{|l|}{$48 \mathrm{~h}$} \\
\hline Iodine solution & 0 & 0 & 0 & 4 & 4 & 2 & 0 & 0 & 0 & 0 & 0 & 0.312 & 0.625 & $<0.001$ \\
\hline \multicolumn{15}{|l|}{$72 \mathrm{~h}$} \\
\hline Peracetic acid & 2 & 0 & 8 & 0 & 0 & 0 & 0 & 0 & 0 & 0 & 0 & 0.078 & 0.078 & \multirow[t]{3}{*}{$<0.001$} \\
\hline Sodium hypochlorite & 0 & 0 & 0 & 0 & 4 & 5 & 1 & 0 & 0 & 0 & 0 & 0.625 & 0.625 & \\
\hline Iodine solution & 0 & 0 & 0 & 0 & 7 & 3 & 0 & 0 & 0 & 0 & 0 & 0.312 & 0.625 & \\
\hline
\end{tabular}

${ }^{1}$ In vitro assays considering isolates $(\mathrm{n}=10)$ of $P$. zopfii.

${ }^{2} \mathrm{MIC}_{50}$ and $\mathrm{MIC}_{90}$ refer to MIC required to inhibit growth of $50 \%$ and $90 \%$, respectively, of P. zopfii isolates tested.

${ }^{3}$ Difference in the survival strata (concentration at inhibition) was tested via log-rank and Wilcoxon tests.

Our scanning electron microscopy results were similar to those of Costa et al. (2004). However, in the images shown by Costa et al. (2004), cellular clustering of $P$. zopfii originated from an isolate from a clinical case of bovine mastitis, suggesting that, regardless of the type of mastitis, microalgae may produce biofilms.

Davies (2003) reported that conventional antimicrobial treatments are generally incapable of eliminating biofilms, which can result in chronic infection caused by bacteria. Based on results described by Costa et al. (1996), mastitis caused by Prototheca spp. is not responsive to treatment; thus, control of this disease should focus on prevention strategies.

\section{Resistance Profile of Prototheca spp. to Sanitizers Determined by MIC}

We detected a significant effect of sanitizer and incubation time $(24,48$, and $72 \mathrm{~h}$ ) on MIC values against P. zopfii isolates (Table 2). The longer the incubation period, the higher the concentration of sanitizer needed to prevent reproduction of the $P$. zopfii isolates. Lassa et al. (2011) evaluated the effectiveness of 3 sanitizers at preventing reproduction of $P$. zopfii; however, in contrast to the present study, they reported that the efficiency of the sanitizer depends more on the concentration used than on the incubation period.

All $P$. zopfii isolates were sensitive to the 3 sanitizers at 24,48 , and $72 \mathrm{~h}$ of incubation. After $24 \mathrm{~h}$ of incubation, $P$. zopfii isolates were sensitive in vitro to peracetic acid $\left(\mathrm{MIC}_{90} \geq 0.019 \mathrm{~g} / \mathrm{L}\right)$, sodium hypochlorite $\left(\mathrm{MIC}_{90}\right.$ $\geq 0.312 \mathrm{~g} / \mathrm{L}$ ), and iodine solution $\left(\mathrm{MIC}_{90} \geq 0.625 \mathrm{~g} / \mathrm{L}\right)$. Similar to the present study, Lassa et al. (2011) assessed the efficiency of teat sanitizers in vitro (iodine, didecyldimethylammonium, and dodecylbenzenesulfonic acid) on reproduction of $P$. zopfii. In that study, of the 3 sanitizers, iodine had the greatest efficiency for prevention of mastitis caused by $P$. zopfii. However, the concentration of iodine $(0.1 \mathrm{~g} / \mathrm{L})$ that prevented multiplication of $P$. zopfii after $12 \mathrm{~h}$ of incubation was less than the $\mathrm{MIC}_{90}$ described in the present study $(0.625$ $\mathrm{g} / \mathrm{L})$, after $24 \mathrm{~h}$ of incubation.

Studies evaluating the use of sanitizers to reduce contamination of utensils and milking and dairy farm equipment or to prevent the IMI caused by $P$. zopfii are scarce (Cunha et al., 2010; Marques et al., 2010a; Lassa et al., 2011). Marques et al. (2010a) assessed effects of different salt concentrations and $\mathrm{pH}$ on Prototheca spp. resistance, and observed that $P$. zopfii had reproduction capacity in all of the $\mathrm{pH}$ buffers except to acetic acid. In the present study, the sanitizer that had the greatest efficiency (lowest MIC) was peracetic acid. The higher efficiency of peracetic acid may be due to its high oxidating potential and molecular weight, which is similar to that of acetic acid. Indole-3 acetic acid combined with horseradish peroxidase (IAA/HRP) had cytotoxic effects on $P$. zopfii (Cunha et al., 2010). Furthermore, in response to exposure to the IAA/HRP, cellular viability and colony production of P. zopfii were reduced. In another study, the use of teat sanitizers was evaluated and, in contrast to the present study, iodine was the most efficient sanitizer (Lassa et al., 2011).

\section{CONCLUSIONS}

Prototheca zopfii isolates are capable of producing biofilms that may contribute to persistence of this species in milking environments and the milk-processing 
industries. Prototheca zopfii is sensitive in vitro to peracetic acid $\left(\mathrm{MIC}_{90} \geq 0.019 \mathrm{~g} / \mathrm{L}\right)$, sodium hypochlorite $\left(\mathrm{MIC}_{90} \geq 0.312 \mathrm{~g} / \mathrm{L}\right)$, and iodine $\left(\mathrm{MIC}_{90} \geq 0.625 \mathrm{~g} / \mathrm{L}\right)$ after $24 \mathrm{~h}$ of incubation. However, the longer the incubation period, the greater the concentration of sanitizer needed to prevent reproduction of the $P$. zopfii isolates. Among the tested sanitizers, peracetic acid was more effective than sodium hypochlorite or iodine.

\section{ACKNOWLEDGMENTS}

The authors are grateful to the Fundação de Amparo à Pesquisa do Estado de São Paulo, Brazil (FAPESP; São Paulo, Brazil) for scholarship (grant no. 2013/23613-8). The authors acknowledge Bruna Leonel Goncalves (graduate student of Department of Food Engineering, School of Animal Sciences and Food Engineering, SASFE/USP), Silvia Helena Seraphin de Godoy (Laboratory Technician of Department of Veterinary Medicine, SASFE/USP), Rodrigo Vinicius Lourenço (Laboratory Technician of Department of Food Engineering, SASFE/USP), Romulo Germano de Rezende, and Mariane Ceschin Ernandes (graduate student of Department of Animal Sciences, School of Veterinary Medicine and Animal Sciences, University of São Paulo) for technical assistance.

\section{REFERENCES}

Bradley, A., and M. Green. 2005. Use and interpretation of somatic cell count data in dairy cows. Farm Anim. Pract. 27:310-315.

Buzzini, P., B. Turchetti, R. Facelli, R. Baudino, F. Cavarero, L. Mattalia, P. Mosso, and A. Martini. 2004. First large-scale isolation of Prototheca zopfii from milk produced by dairy herds in Italy. Mycopathologia 158:427-430.

Camboim, E. K. A., P. B. Neves, F. Garino Júnior, J. M. Medeiros, and F. Riet-Correa. 2010. Prototecose: Uma doença emergente. Pesqui. Vet. Bras. 30:94-101.

Chandra, J., P. K. Mukherjee, and M. A. Ghannoum. 2008. In vitro growth and analysis of Candida biofilms. Nat. Protoc. 3:19091924.

Corbellini, L. G., D. Driemeier, C. Cruz, M. M. Dias, and L. Ferreiro. 2001. Bovine mastitis due to Prototheca zopfii: Clinical, epidemiological and pathological aspects in a Brazilian dairy herd. Trop. Anim. Health Prod. 33:463-470.

Cortinhas, C. S., L. Oliveira, C. A. Hulland, M. V. Santos, and P. L. Ruegg. 2013. Minimum inhibitory concentrations of cephalosporin compounds and their active metabolites for selected mastitis pathogens. Am. J. Vet. Res. 74:683-690.

Costa, E. O., P. A. Melville, A. R. Ribeiro, E. T. Watanabe, and M. C. Parolari. 1997. Epidemiologic study of environmental sources in a Prototheca zopfii outbreak of bovine mastitis. Mycopathologia $137: 33-36$

Costa, E. O., A. R. Ribeiro, P. A. Melville, M. S. Prada, A. C. Carciofi, and E. T. Watanabe. 1996. Bovine mastitis due to algae of the genus Prototheca. Mycopathologia 133:85-88.

Costa, E. O., M. G. Ribeiro, A. R. Ribeiro, N. S. Rocha, and G. de Nardi Junior. 2004. Diagnosis of clinical bovine mastitis by fine needle aspiration followed by staining and scanning electron microscopy in a Prototheca zopfii outbreak. Mycopathologia 158:8185.
Cunha, L. T., S. M. Pugine, M. R. Silva, E. J. Costa, and M. P. De Melo. 2010. Microbicidal action of indole-3-acetic acid combined with horseradish peroxidase on Prototheca zopfii from bovine mastitis. Mycopathologia 169:99-105.

Davies, D. 2003. Understanding biofilm resistance to antibacterial agents. Nat. Rev. Drug Discov. 2:114-122.

Gerstel, U., and U. Romling. 2001. Oxygen tension and nutrient starvation are major signals that regulate agfD promoter activity and expression of the multicellular morphotype in Salmonella typhimurium. Environ. Microbiol. 3:638-648.

Gibson, H., J. H. Taylor, K. E. Hall, and J. T. Holah. 1999. Effectiveness of cleaning techniques used in the food industry in terms of the removal of bacterial biofilms. J. Appl. Microbiol. 87:41-48.

Huss, V. A. R., C. Frank, E. C. Hartmann, M. Hirmer, A. Kloboucek, B. M. Seidel, P. Wenzeler, and E. Kessler. 1999. Biochemical taxonomy and molecular phylogeny of the genus Chlorella sensu lato (chlorophyta). J. Phycol. 35:587-598.

Jánosi, S., G. Szigeti, F. Ratz, T. Lauko, J. Kerenyi, M. Tenk, F Katona, A. Huszenicza, M. Kulcsar, and G. Huszenicza. 2001. Prototheca zopfii mastitis in dairy herds under continental climatic conditions. Vet. Q. 23:80-83.

Kadouri, D., and G. A. O'Toole. 2005. Susceptibility of biofilms to Bdellovibrio bacteriovorus attack. Appl. Environ. Microbiol. 71:4044-4051.

Knobloch, J. K., K. Bartscht, A. Sabottke, H. Rohde, H. H. Feucht, and D. Mack. 2001. Biofilm formation by Staphylococcus epidermidis depends on functional RsbU, an activator of the sigB operon: Differential activation mechanisms due to ethanol and salt stress. J. Bacteriol. 183:2624-2633.

Lass-Flörl, C., and A. Mayr. 2007. Human protothecosis. Clin. Microbiol. Rev. 20:230-242

Lassa, H., T. Jagielski, and E. Malinowski. 2011. Effect of different heat treatments and disinfectants on the survival of Prototheca zopfii. Mycopathologia 171:177-182.

Lee, S. H. I., B. L. C. Mangolin, J. L. Gonçalves, D. V. Neeff, M. P. Silva, A. G. Cruz, and C. A. F. Oliveira. 2014. Biofilm-producing ability of Staphylococcus aureus isolates from Brazilian dairy farms. J. Dairy Sci. 97:1812-1816.

Marques, S., E. Silva, J. Carvalheira, and G. Thompson. 2006. Short communication: In vitro antimicrobial susceptibility of Prototheca wickerhamii and Prototheca zopfii isolated from bovine mastitis. J. Dairy Sci. 89:4202-4204.

Marques, S., E. Silva, J. Carvalheira, and G. Thompson. 2010a. In vitro susceptibility of Prototheca to $\mathrm{pH}$ and salt concentration. Mycopathologia 169:297-302.

Marques, S., E. Silva, J. Carvalheira, and G. Thompson. 2010b. Short communication: Temperature sensibility of Prototheca blaschkeae strains isolated from bovine mastitic milk. J. Dairy Sci. 93:51105113.

Marques, S., E. Silva, C. Kraft, J. Carvalheira, A. Videira, V. A. R. Huss, and G. Thompson. 2008. Bovine mastitis associated with Prototheca blaschkeae. J. Clin. Microbiol. 46:1941-1945.

Melville, P. A., E. Watanabe, N. Benites, A. Ribeiro, J. B. Silva, F. Garino Jr., and E. Costa. 1999. Evaluation of the susceptibility of Prototheca zopfii to milk pasteurization. Mycopathologia 146:79-82

Möller, A., U. Truyen, and U. Roesler. 2007. Prototheca zopfii genotype 2: The causative agent of bovine protothecal mastitis? Vet. Microbiol. 120:370-374.

Nagai, T., K. Taya, H. Annoh, and S. Ishihara. 2013. Application of a fluorometric microplate algal toxicity assay for riverine periphytic algal species. Ecotoxicol. Environ. Saf. 94:37-44.

NCCLS (National Committee for Clinical Laboratory Standards). 2000. Methods for dilution antimicrobial susceptibility tests for bacteria that grow aerobically. Fifth edition. Approved Standard M7-A5. NCCLS, Wayne, PA.

Oliver, S. P. O., R. N. González, J. S. Hogan, B. M. Jayarao, and W. E. Owens. 2004. Microbiological Procedures for the Diagnosis of bovine udder infection and determination of milk quality. Pages 
1-40, 44-46 in A Global Organization for Mastitis Control and Milk Quality. 4th ed. National Mastitis Council Inc., Verona, WI.

Osumi, T., Y. Kishimoto, R. Kano, H. Maruyama, M. Onozaki, K. Makimura, T. Ito, K. Matsubara, and A. Hasegawa. 2008. Prototheca zopfii genotypes isolated from cow barns and bovine mastitis in Japan. Vet. Microbiol. 131:419-423.

Pieper, L., A. Godkin, U. Roesler, A. Polleichtner, D. Slavic, K. E. Leslie, and D. F. Kelton. 2012. Herd characteristics and cow-level factors associated with Prototheca mastitis on dairy farms in Ontario, Canada. J. Dairy Sci. 95:5635-5644.

Pompermayer, D. M. C., and C. C. Gaylarde. 2000. The influence of temperature on the adhesion of mixed cultures of Staphylococcus aureus and Escherichia coli to polypropylene. Food Microbiol. $17: 361-365$.
Ricchi, M., M. Goretti, E. Branda, G. Cammi, C. A. Garbarino, B. Turchetti, P. Moroni, N. Arrigoni, and P. Buzzini. 2010. Molecular characterization of Prototheca strains isolated from Italian dairy herds. J. Dairy Sci. 93:4625-4631.

Roesler, U., and A. Hensel. 2003. Longitudinal analysis of Prototheca zopfii-specific immune responses: correlation with disease progression and carriage in dairy cows. J. Clin. Microbiol. 41:1181-1186.

Sambrook, J., E. Fritsch, and T. Maniatis. 1989. Molecular Cloning: A Laboratory Manual, Books 1-3. 2nd ed. Cold Spring Harbor Laboratory Press, Cold Spring Harbor, NY.

Stepanović, S., I. Cirković, V. Mijač, and M. Švabić-Vlahović. 2003. Influence of the incubation temperature, atmosphere and dynamic conditions on biofilm formation by Salmonella spp. Food Microbiol. 20:339-343. 